\title{
Psychiatry and the Public School
}

Julie Chalmers, Senior Registrar, Warneford Hospital, Oxford and R. A. Hope, Wellcome Trust Training Fellow, Department of Psychiatry, University of Oxford

From the back of the school hall a boy spoke: 'If you agree to play cricket you can hardly complain when they put the fast bowlers on against you.' Eighty of his fellow sixthformers laughed, but his view differed little from most of theirs. The discussion was about ECT.

One of the pleasures of becoming full members of the Royal College is that we are considered to be experts in psychiatry. It was as such that we were asked to speak to a group of 80 sixth-form boys at a local public school. The title we were given was: 'What is psychiatry?'. This was as part of a course in liberal studies. The week before a local general practitioner had given a lecture on Health. The week after a local solicitor would give a talk on Law. Our brief was the Mind.

What should we teach a group of sixth-formers about psychiatry? We thought it important that they should know that psychiatry is a part of medicine and that its day to day practice consists in helping people with problems and stresses, not in wrestling with dangerous lunatics. In the introduction to our presentation we stressed the point that everyone is capable of psychological distress which may benefit from professional help and that such distress is not moral weakness. We wanted to dispel the stigma that is attached to being psychiatrically ill, and to give some basic information, but we also wanted to stimulate and to entertain.

\section{Case history}

We handed out a typescript to each student with a case history followed by some questions which we hoped would be the focus for further discussion. This history was as follows:

Mrs Chapman is a 28 year-old married woman with two children, a boy aged $4 \frac{1}{2}$ years and a girl aged $2 \frac{1}{2}$ years. She has been married for six years to a secondary school teacher. She worked full-time as a librarian until the birth of her son, since when she has not worked outside the home.

Four months ago she became interested in the plight of the Ethiopian people and organised local collections. Two months ago her husband noticed that she was becoming increasingly upset by the famine in Ethiopia. She cried several times a day, and she no longer had the energy to collect. She said this was because she was sleeping badly, waking at 3 a.m. feeling miserable and unable to get back to sleep.

She went to her general practitioner four weeks ago, who gave her a prescription for sleeping pills.

Since then she has become more miserable, and has not taken her usual care with the house and her children. Her husband became particularly alarmed when he found two empty bottles of sherry at the bottom of her wardrobe.

One week ago, she went shopping in Tesco's. At the checkout she was stopped by security staff and found to have a bottle of Tesco's Cream Sherry in her overcoat pocket. She then broke down, admitting that she had stolen the sherry and 'confessed' to being the cause of the Ethiopian famine.
Her general practitioner referred her for an urgent psychiatric opinion.

Role play

It was now time to use the stage. One of us was Mrs Chapman. She looked miserable, spoke slowly and quietly. The other of us, of a less dramatic predilection, acted the psychiatrist. We attempted to illustrate that Mrs Chapman firmly held the belief that she was responsible, in some way, for the famine in Ethiopia, and that only since her mood had been low had she been drinking excessively. We established that her taking the bottle of sherry had been quite out of character and that she could remember little of what had happened in the shop. The psychiatrist suggested that she should be admitted to hospital as she appeared to be suffering from a depressive illness and this would give the opportunity both to understand her better and to start treatment as necessary. Mrs Chapman replied that she would be willing to come into hospital only if the psychiatrist promised never to use 'that electrical treatment'.

\section{The questions}

We stopped the role-play at that point and asked the boys the following questions:

(a) If you were the psychiatrist, which of the following actions do you think you should take?

(i) To tell Mrs Chapman that you may well want to use ECT, and then let her decide whether she should come into hospital or not.

(ii) To tell Mrs Chapman that you may want to use ECT and if she doesn't come into hospital to enforce her admission to hospital.

(iii) You promise her that you will never use ECT and she comes into hospital voluntarily.

(a) You then don't use ECT.

(b) You then enforce the use of ECT.

(iv) Is there any other option you would like to take? Please specify.

(b) Do you think the use of ECT is ever justified?

(c) Do you think that a Court should find her:

(i) guilty of theft;

(ii) punish her accordingly?

Before writing answers to these questions we suggested that they might wish for more factual information. They required no prompting from us to ask immediately what ECT actually involved, whether there were alternative treatments and what the long term effects of the different treatments were likely to be. At this stage we answered only questions of fact. It was not until the boys had finished writing answers to the above questions that we allowed the discussion to range over the ethical issues. Unfortunately there was only a quarter of an hour remaining and this was certainly not long enough to do justice to the variety of views that the boys had. One boy argued forcefully for the 
respect of the autonomy of the patient and against treating her against her will. If her mental state were such that she was responsible for her actions, it was such that her wishes should be respected even if the doctor thought that the decision she made was not in her best interests. Another boy was interested in the views of the Church on treatment with ECT. Underlying this interest was the question of whether ECT raises issues that are profoundly different from those raised by other treatments, but we had not left time to explore this. The variety of views held were only fully appreciated by us when we read the written answers.

\section{The answers}

The trust in and the respect for the authority of doctors shown by many of the boys was a surprise for us - children as we were of the sixties! When we asked whether ECT was ever justified, typical answers were: 'Yes, if the psychiatrist thinks that it is the best treatment.' 'Yes, in all cases where psychiatrists advise it.'

One student had little time for the patient who goes to the doctor complaining of depression and then refuses ECT treatment-hence the remark about cricket.

Although there was this general respect for authority we were struck more by the disagreements and these centred around five main issues.

(1) Autonomy versus paternalism Is ECT ever justified? Four boys thought that it was justified only with Mrs Chapman's permission. One boy wrote: 'Not if the patient has expressly said she doesn't want it. Only if positive consent is given after the exact process has been explained.' But such answers were the exception. These are more typical: 'Yes, if the opinion of two or more psychiatrists has been consulted: they know better than a patient what to do.'

A more sophisticated answer was this: 'If it is against her will you could try and persuade her to go through with this. If this fails it is in her best interests for her to undergo ECT treatment forcibly (however I believe she could be persuaded). If you believe ECT is right for her, her refusal should not change your decision. You are the authority.'

A clear statement of the paternalistic position is provided by this answer: 'Yes, if treatment would do more good than no treatment.'

(2) Society versus the individual Several of the boys mentioned the interests of society. Some went so far as to see Mrs Chapman as dangerous in the light of her possible theft. Thus in answering the question about punishment one boy wrote: 'No, but the Court should make sure that she gets treatment for her illness which at the moment is causing her to be a danger to society.'

Another wrote: 'Yes, to maintain the principles of law and order and to discourage potential thieves. Due to the difficulty in technically rather than morally definitely excusing guilt, the offender should be judged guilty.'

The interests of the family were specifically mentioned by one boy who wrote that ECT was justified: 'If the person is responsible for others, e.g., a family, otherwise only if the person wants it.'

(3) Means versus ends Most boys thought that it was not right for a patient to be told a lie in order to obtain desirable ends. However, in answer to the first question one boy wrote: 'Try to convince her that ECT may be beneficial. If she still refuses then promise you won't use it. When she gets to hospital if it is thought that ECT may help then give her the anaesthetic under false pretences. If she suspects what you are doing and still refuses, then use drugs or something else. I don't think that she should be manually forced to do anything.'

(4) Is treatment punishment? One boy wrote: 'the correct punishment for her would be psychiatric help, not a fine.' For another: 'Hospital treatment for two months is sufficient punishment.' Another considered that ECT is punishment and for that reason he thought that it should be given only to the 'criminally insane'. Another boy clearly distinguished treatment from punishment. In answer to the last question he wrote: 'No, just treatment. Suspend punishment until later.'

(5) Is ECT fundamentally different from drug treatment? The question of whether ECT raises ethical issues that are different from those raised by drug treatment was brought up in the discussion. From the written answers it was clear that there was disagreement on this issue. One boy wrote rhetorically: 'Is there much difference ethically between the ECT and drug treatment?'

Another wrote, however: 'The use of ECT on people who could be cured by normal means is not acceptable to me.'

Conclusions

Had we answered the question: 'What is psychiatry?' Perhaps it is as unanswerable as Joxer's question: 'What is the stars?' This was the first time that either of us had talked to so large a group of sixth formers. In retrospect we wonder whether we could have improved both the content and the style of our presentation. We chose a rather unusual case as the focus for most of the discussion, and used this to challenge the boys intellectually by raising issues of ethical concern. What we had not done was to give a picture of what an average day is like in the life of a psychiatrist, and so our presentation would have been of little use for career guidance. However more of our audience are likely at some stage to require psychiatric help than to become psychiatrists, and perhaps we should have used this opportunity to address that issue. In these days when the maintenance of physical health is so fashionable, we could have tackled the more original topic of the maintenance of mental health.

The style of our presentation appeared to be effective in stimulating discussion. The use of rôle play enlivened the proceedings but many people may be less comfortable with this format. Some of the excellent teaching videos using actors could be equally valuable. A disadvantage of the rôle play was that it imposed a topic on the audience and it may have been more interesting to see which points the boys would have chosen to raise unprompted by us.

Whether or not we chose either the best form or content it was an exciting experience for us and it provoked a lively response from the audience. The discussion continued after the end of the session. Over tea the boys bowled questions at us in rapid succession. We could hardly complain: we had agreed to play the game. 